1. MBBS, FCPS

Assistant Professor Paediatrics Hamdard College of Medicine and Dentistry Hamdard University Hospital, Karachi.

2. MBBS, FCPS

Senior Registrar Paediatrics Shaheed Muhtrama Benazir Bhutto Medical College

Layari General Hospital Karachi.

3. MBBS, MCPS, FCPS

Assistant Professor Paediatrics Shaheed Muhtrama Benazir Bhutto Medical College

Layari General Hospital Karachi.

4. MBBS, FCPS

Assistant Professor Pediatrics Dow University of Health Sciences/ Civil Hospital Karachi.

5. MBBS, FCPS

Senior Registrar Pediatrics

National Institute of Child Health Karachi.

6. MBBS, FCPS

Associate Professor Gyne \& Obs Shaheed Muhtrama Benazir Bhutto Medical College

Layari General Hospital Karachi.

Correspondence Address:

Dr. Nathumal Maheshwari

Department of Paediatrics

Shaheed Muhtrama Benazir Bhutto

Medical College

Layari General Hospital, Karachi.

drnathumal@gmail.com

Article received on:

04/11/2019

Accepted for publication:

25/04/2020

\section{PHOTOTHERAPY IN FULL TERM NEONATES SUFFERING FROM UNCONJUGATED HYPERBILIRUBINEMIA; DOES IT AFFECT PLATELET COUNT?}

Adnan Bashir ${ }^{1}$, Ashok Kumar ${ }^{2}$, Nathumal Maheshwari ${ }^{3}$, Bilawal Hingorjo ${ }^{4}$, Shakeel Ahmed ${ }^{5}$, Saher Fatima ${ }^{6}$

ABSTRACT... Objectives: Investigating the hazardous effect of Phototherapy on Platelet counts in healthy neonates with Neonatal hyperbilirubinemia (NH). Study Design: Cross Sectional study. Setting: Department of Paediatrics, SMBB Medical College Layari General Hospital, Karachi, Sindh. Period: January 2018 to May 2019. Material \& Methods: A sample of 313 neonates suffering from $\mathrm{NH}$ was selected according to the inclusion and exclusion criteria. Blood Platelets were counted at baseline, and 24, 48 and 72 hours of phototherapy. Statistical software SPSS 21.0 (IBM, Incorp, USA) was used for data analysis using paired t-test and Pearson's Chi- square test at $P \leq 0.05$. Results: Platelet counts at 24,48 and 72 hours of phototherapy were found $2.97 \pm 0.45 \times 10^{9} / \mathrm{L}, 3.38 \pm 0.48 \times 10^{9} / \mathrm{L}$ and $3.52 \pm 0.47 \times 10^{9} / \mathrm{L}$ respectively. Platelet counts at 24,48 and 72 hours showed statistically significant difference compared to baseline counts $(\mathrm{P}<0.05)$. A statistically insignificant decline in total population platelet count after phototherapy was noted $(P>0.05)$. However, thrombocytopenia was noted in 9 (2.87\%) cases; comprising mild and moderate in $7(2.23 \%)$ and $2(0.64 \%)$ cases respectively. Conclusion: The present study observed thrombocytopenia in $9(2.87 \%)$ of total cases; of which mild and moderate thrombocytopenia occurred in 7 (2.23\%) and $2(0.64 \%)$ cases respectively.

Key words: $\quad$ Neonatal Hyperbilirubinemia, Phototherapy, Platelet Count.

Article Citation: Bashir A, Kumar A, Maheshwari N, Hingorjo B, Ahmed S, Fatima S. Phototherapy in full term neonates suffering from unconjugated hyperbilirubinemia; Does it affect platelet count? Professional Med J 2020; 27(9):1911-1915. DOI: 10.29309/TPMJ/2020.27.09.4320

\section{INTRODUCTION}

Yellow discoloration of eye sclera, skin and mucosa surfaces is a common physical finding in majority of newborns. It occurs due to elevated serum bilirubin levels called the Neonatal hyperbilirubinemia $(\mathrm{NH})$. The $\mathrm{NH}$ is commonest physical finding of first week of neonatal life. Prevalence of $\mathrm{NH}$ is approximately $60 \%$ in full term neonates and $80 \%$ in pre- term neonates. ${ }^{1,2}$ Full term neonates show serum bilirubin $\geq 12.9 \mathrm{mg} \%$. Majority of term neonates shows serum bilirubin $\geq 15 \mathrm{mg} \%$ that has been reported in $3 \%$ cases. $\mathrm{NH}$ is a characterized by accumulation of unconjugated/indirect bilirubin that is highly toxic because of lipid soluble nature. It penetrates into cells in particular the neuronal tissue causing neurotoxicity. ${ }^{2}$ Indirect bilirubin produces encephalopathy, neuronal damage leading subsequently to kernicterus. The kernicterus manifests as devastating permanent brain injury leading eventually to permanent brain retardation..$^{3-5}$ The $\mathrm{NH}$ occurs because of imbalance of liver functioning due to immaturity and increased bilirubin load to detoxify. This results in lagging behind of bilirubin in capillaries giving an appearance of yellowness (jaundice). As the liver matures, this $\mathrm{NH}$ disappears but the danger is of neurotoxic bilirubin that damages brain hence necessitates therapeutic intervention to prevent complications. ${ }^{6} \mathrm{NH}$ is the most common cause of neonatal re- hospitalization. It is a cause of concern for the parents, family members and the pediatrician too. ${ }^{7}$ Premature neonates have high incidence of $\mathrm{NH}$ that necessitates for therapeutic intervention. Timely intervention with appropriate measure is of paramount importance for this condition. Therapeutic interventions for the $\mathrm{NH}$ include; phototherapy, 
exchange blood transfusion, or pharmacologic agents like clofibrate, metalloporphyrins and phenobarbitones. Phenobarbitones are excellent liver enzyme induces to detoxify but at the cost of adverse drug reactions.

Phototherapy (PT) has shown excellent results at low or none side effects. PT is now the most widely used treatment for the $\mathrm{NH}$ over the globe. The PT is a inexpensive, simple and easily available therapeutic measures that is practiced widely. An effective and timely intervention of PT may prevent severe complications of hyperbilirubinemia. General perception of PT is that it is an innocent, safe and effect method of treatment for $\mathrm{NH}$ free from side effects. However, many adverse effects have been reported in the medical literature..$^{3-6}$ Reported side effects of PT are; dehydration due to insensible water loss, hyperthermia, skin rash, retinal damage, loose stool, hypocalcemia, risk of patent ductus arteriosus, hypocalcemia, skin damage, and genotoxicity. ${ }^{8,9}$ Previous human studies ${ }^{8-10}$ suggested phototherapy causes the low blood platelet counts called the thrombocytopenia.

This adverse effect of phototherapy is lacking from the Standard Pediatrics Textbooks, but many authors have reported on the occurrence of thrombocytopenia while others reported inconclusive and controversial outcome. Due to the scarcity of studies from the country, the authors proposed a research protocol to study and analyze the adverse effects of PT. The present study was conducted to evaluate the effects of phototherapy on the blood platelets and white cells in neonatal hyperbilirubinemia treated at our tertiary care hospital.

\section{MATERIAL \& METHODS}

The present cross sectional study was conducted at the Neonatology unit, Department of Paediatrics, Shaheed Muhtrama Benazir Bhutto (SMBB) Medical College Layari General Hospital, Karachi, Sindh. The study covered duration of January 2017 to March 2019. A sample of 313 neonates suffering from unconjugated hyperbilirubinemia being treated by phototherapy was selected according to the inclusion and exclusion criteria of study protocol. Research proposal was presented to the ethical review committee of the institute for ethical review and approval. A proforma was designed for the data collection along with informed consent proforma.

Neonates presenting with clinical jaundice were observed for inclusion and exclusion criteria to be enrolled for study protocol. Full term Neonates suffering from neonatal unconjugated hyperbilirubinemia $(\mathrm{NH})$ were investigated for the baseline platelet counts, serum bilirubin and ABO blood groups. Neonates with unconjugated hyperbilirubinemia demanding PT were included. Inclusion criteria were; neonatal jaundice otherwise apparently healthy neonates, age; 2 - 28 days, negative Direct Coomb's test and normal C-reactive protein (CRP). Neonates were examined to exclude the sepsis, septicemia, renal failure, DIC, congenital thrombocytopenia, toxoplasmosis, and viral infections. Baseline low platelet counts, readmission for neonatal hyperbilirubinemia, ABO and Rh incompatibility, birth asphyxia, direct hyperbilirubinemia were also excluded.

Collection of venous blood samples was performed under strict aseptic measures was taken properly. $2 \mathrm{ml}$ blood was taken by venesection, kept into sodium fluoride tubes for platelet counts and remaining blood was centrifuged to get sera for biochemical testing. Platelet counts were measured by Hematology Auto-analyzer (Sysmex KX, 21). Serum bilirubin was detected by diazo method (Diazotized sulphanilic test). Blood Platelets were counted at baseline, and 24, 48 and 72 hours post phototherapy. Thrombocytopenia was defined as $<150 \times 10^{9} / \mathrm{L}$. Mild, moderate and severe thrombocytopenia was categorized as; mild 100 - 150×10\%/L, moderate $50-100 \times 10^{9} / \mathrm{L}$ and severe as $<50 \times 10^{9} / \mathrm{L}$. Data was typed in Excel sheet and analyzed in Statistical software SPSS 21.0 (IBM, Incorp, USA). Numerical data was analyzed by Student's (paired) t-test and categorical data by Pearson `s Chi- square test at 95\% Confidence interval $(P \leq 0.05)$.

\section{RESULTS}


Mean \pm SD age of sample population was $4.14 \pm$ 1.6 days. Most common presentation of neonatal hyperbilirubinemia was noted on day $3(24.62 \%)$, day $4(19.47 \%)$ and day $2(18.21 \%)(P=0.0001)$ (Table-l/Figure-1). Range of age of presentation was 2- 8 days of neonatal life. Of 313 sample; 161 $(51.4 \%)$ were male and $152(48.5 \%)$ were female $(P=0.71)$ (Table-II). Baseline serum bilirubin (Mean $\pm \mathrm{SD}$ ) was $17.56 \pm 1.39 \mathrm{mg} / \mathrm{dl}$, while follow up bilirubin was $13.05 \pm 1.35 \mathrm{mg} / \mathrm{dl}$. Baseline platelet count was $3.67 \pm 0.41 \times 10^{9} / \mathrm{L}$. Platelet counts at 24, 48 and 72 hours after Phototherapy were noted as $2.97 \pm 0.45 \times 10^{9} / \mathrm{L}, \quad 3.38 \pm 0.48 \times 10^{9} / \mathrm{L}$ and $3.52 \pm 0.47 \times 10^{9} / \mathrm{L}$ respectively. The Platelet counts at 24,48 and 72 hours showed statistically significant difference compared baseline platelet counts $(P<0.05)$ (Table-III). Decline in Platelet counts was noted in $60.3 \%$. Thrombocytopenia was noted in total $9(2.87 \%)$ cases; of which mild and moderate thrombocytopenia were observed in $7(2.23 \%)$ and $2(0.64 \%)$ respectively (TableIV). Severe thrombocytopenia was not observed in the present study.

\begin{tabular}{|c|c|c|c|}
\hline Age (days) & Frequency & $\%$ & P-Value \\
\hline 2 & 57 & 18.21 & \multirow{8}{*}{0.0001} \\
\hline 3 & 77 & 24.62 & \\
\hline 4 & 61 & 19.47 & \\
\hline 5 & 47 & 15.01 & \\
\hline 6 & 39 & 12.47 & \\
\hline 7 & 17 & 5.43 & \\
\hline 8 & 15 & 4.79 & \\
\hline Total & 313 & 100 & \\
\hline \multicolumn{4}{|c|}{ Table-I. Age distribution study subjects $(n=313)$} \\
\hline
\end{tabular}

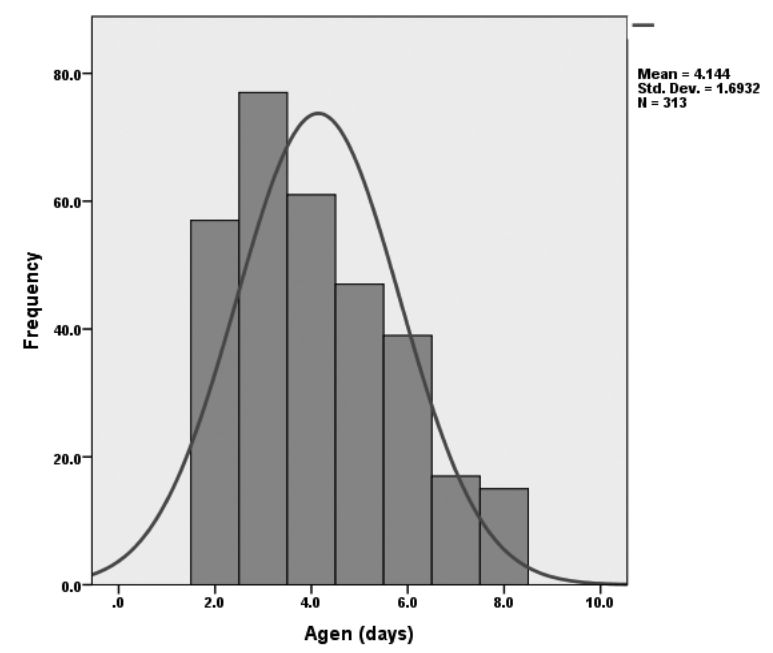

Figure-1. Age distribution of study subjects

\begin{tabular}{|l|c|c|c|}
\hline \multicolumn{1}{|c|}{ Gender } & No. & $\%$ & P-Value \\
\hline Male & 161 & 51.4 & \\
\hline Female & 152 & 48.5 & 0.71 \\
\hline Total & 313 & 100 & \\
\hline
\end{tabular}

Table-II. Gender distribution of study subjects $(n=313)$

\begin{tabular}{|l|c|c|c|}
\hline Platelet Counts & Mean & SD & SEM \\
\hline Baseline $\left(\times 10^{9} / \mathrm{L}\right)$ & 3.67 & 0.41 & 0.022 \\
\hline 24 hours $\left(\times 10^{9} / \mathrm{L}\right)$ & 2.97 & 0.45 & 0.025 \\
\hline 48 hours $\left(\times 10^{9} / \mathrm{L}\right)$ & 3.38 & 0.48 & 0.027 \\
\hline 72 hours $\left(\times 10^{9} / \mathrm{L}\right)$ & 3.52 & 0.47 & 0.026 \\
\hline t-value & 19.92 & 9.94 & 16.09 \\
\hline P-value & 0.0001 & 0.0001 & 0.0001 \\
\hline
\end{tabular}

Table-III. Platelet counts after Phototherapy $(n=313)$

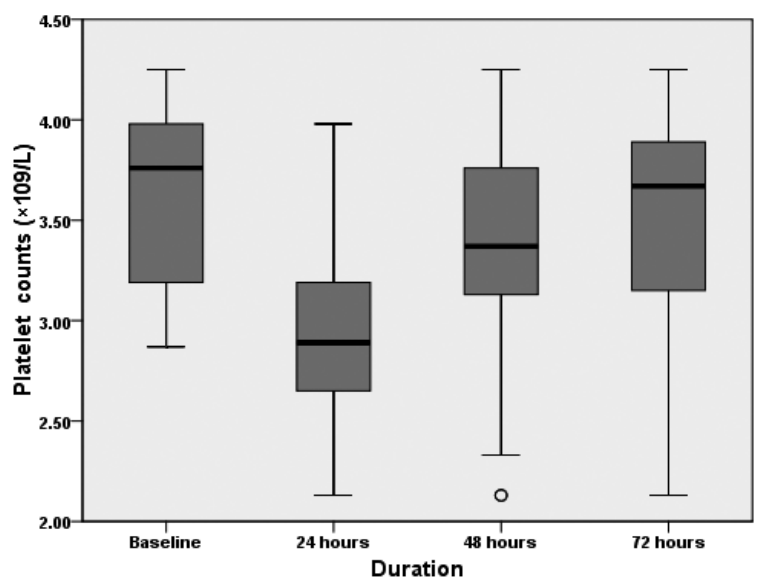

Figure-2. Box plot showing mean and standard deviation of platelet counts at baseline, 24, 48 and 72 hours

\begin{tabular}{|l|c|c|c|}
\hline \multicolumn{1}{|c|}{$\begin{array}{c}\text { Thrombocyto- } \\
\text { penia }\end{array}$} & $\begin{array}{c}\text { Fre- } \\
\text { quency }\end{array}$ & $\%$ & P-Value \\
\hline Mild & 07 & 2.23 & \\
\hline Moderate & 02 & 0.64 & \multirow{2}{*}{0.89} \\
\cline { 1 - 2 } Severe & 0 & 0 & \\
\hline $\begin{array}{l}\text { Absent } \\
\text { (no thrombocyto- } \\
\text { penia) }\end{array}$ & 09 & 2.87 & \\
\hline $\begin{array}{l}\text { Total } \\
\text { Table-IV. Frequency distribution of thrombocytopenia } \\
\text { (n=313) }\end{array}$ \\
\hline
\end{tabular}




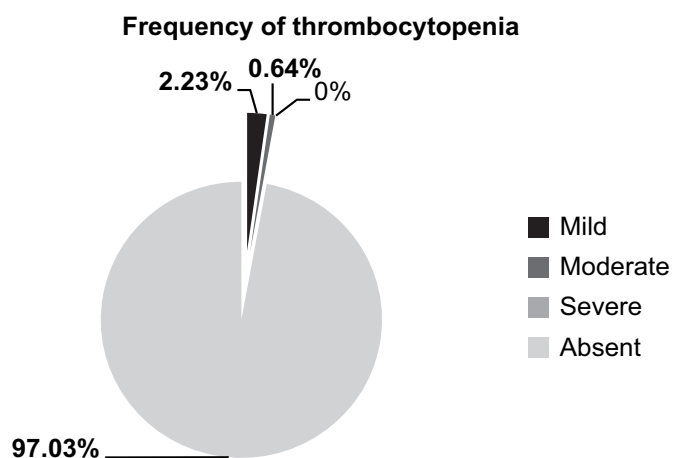

Figure-3

\section{DISCUSSION}

Thepresentstudyinvestigated the hazardouseffect of Phototherapy (PT) on Platelet counts in healthy neonates with unconjugated hyperbilirubinemia $(\mathrm{NH})$. Mean $\pm \mathrm{SD}$ age of sample population was $4.14 \pm 1.6$ days. Most common presentation of neonatal hyperbilirubinemia was noted on day $3(24.62 \%)$, day $4(19.47 \%)$ and day $2(18.21 \%)$. A previous study ${ }^{1}$ reported age (mean \pm SD) of $3.89 \pm 1.83$ days this is consistent with the present study. Findings of Baseline serum bilirubin (Mean \pm SD) of $17.56 \pm 1.39 \mathrm{mg} / \mathrm{dl}$ and follow up bilirubin $13.05 \pm 1.35 \mathrm{mg} / \mathrm{dl}$ is in keeping with the above study ${ }^{1}$, as they reported baseline serum bilirubin levels $17.56 \mathrm{mg} / \mathrm{dl} \pm 1.42$ and followup serum bilirubin was $12.85 \pm 1.65 \mathrm{mg} / \mathrm{dl}$. This in accordance with guideline of PT indication threshold of serum bilirubin levels of $16-18 \mathrm{mg} /$ dl. ${ }^{1}$ In the present study, the Platelet counts at 24 , 48 and 72 hours showed statistically significant difference compared to baseline counts $(P<0.05)$. A statistically insignificant decline in total population platelet count after phototherapy was noted $(P>0.05)$. This is in accordance to the previous studies. ${ }^{2-5,8,10}$

Venaktamurthy et $\mathrm{al}^{10}$ reported similar observations of platelet counts. They reported a decline in platelet counts in total study population after PT, but the difference was non- significant except in low birth babies. Sonawane et al ${ }^{11}$ studied 100 neonates with $\mathrm{NH}$ of which, $58 \%$ were male babies and $48 \%$ were female babies. This is strongly consistent finding with the present study. They ${ }^{11}$ further reported a decline in Platelet Count at 24 hour PT compared to baseline counts. They reported incidence of thrombocytopenia of $2 \%$ noted in 1 term and 1 pre term neonates. The findings of above study ${ }^{11}$ are supporting the present study as thrombocytopenia was noted in total $9(2.87 \%)$ cases; of which mild and moderate thrombocytopenia were observed in 7 (2.23\%) and $2(0.64 \%)$ respectively. However, difference may be because sample size, different ethnicity, provision facilities and human errors.

Vafaie et $\mathrm{al}^{12}$ studied 100 neonates and reported decline in platelet counts in $69 \%$ but the thrombocytopenia was not seen in any case. The of decline in platelet counts of above study is consistent with present study, but no thrombocytopenia is in contrast to present and previous study. ${ }^{11}$ Khera et $\mathrm{al}^{13}$ analyzed platelet counts in PT treated neonates and reported thrombocytopenia in $35 \%$, of them $74 \%$ had mild thrombocytopenia. The incidence of $35 \%$ total thrombocytopenia and $74 \%$ mild thrombocytopenia is very high compared to the total incidence of $2.87 \%$ ) cases; of them mild and moderate thrombocytopenia were observed in 7 $(2.23 \%)$ and $2(0.64 \%)$ respectively. This finding is in contrast to present and previous studies..$^{2-5,8,10}$ They further reported that the most significant decline in platelet counts was in 24 hours PT duration compared to the 48 hours this finding is strongly supportive to the present study as it has noted similar observations.

Pishva et al ${ }^{14}$ reported very high incidence of $49.5 \%$ of thrombocytopenia of total 101 neonates after PT. This is in contrast to present study. However, their finding of low platelet counts prominent during 24 hours PT is strongly consistent with the present study. Highly conflicting findings of above study may be because of the research bias. In the light of conflicting results of published literature it is recommended to conduct prospective studies with large sample size maintaining the internal and external validity of the research to overcome the research bias. The only limitation of present study is a small sample size, however, strength of lays in prospective study design, inclusion and exclusion criteria. As the present study is a hospital based cross sectional, hence the cause 
effect relationship of phototherapy and platelet counts may be ascertained and findings may not be generalized to other settings.

\section{CONCLUSION}

The present study observed thrombocytopenia in $9(2.87 \%)$ oftotal cases; of which mild and moderate thrombocytopenia was noted in 7 (2.23\%) and 2 $(0.64 \%)$ respectively. Severe thrombocytopenia was not observed in present study. In the light of conflicting results of published literature it is recommended to conduct prospective studies with large sample size maintaining the internal and external validity of research to overcome the research bias.

\section{Copyright(C) 25 Apr, 2020.}

\section{REFERENCES}

1. Khaliq A. Comparison of continuous with intermittent phototherapy in the treatment of neonatal jaundice. J Postgrad Med Inst 2016; 30(2): 173-6.

2. Sajid A, Mahmood T, Riaz S, Nabi SG. Phototherapy in Hyperbilirubinemic Neonates; Does it Affect Platelet Count? Ann King Edw Uni 2016; 22 (3): 215-20.

3. Tawab CN, Saldanha PR, Mithun HK. Phototherapy induced thrombocytopenia-a comparative study among breastfed term and preterm neonates with hyperbilirubinemia. Intl J Med Health Sci 2014; 3 (4): 256-60.

4. Tirupathi K, Swarnkar K, Vagha J. Study of risk factors of neonatal thrombocytopenia. Int J Contemp Pediatr 2017; 4:191-6.

5. Boskabadi H, Mafinezhad S, Bagher F. Incidence of Thrombocytopenia in Idiopathic Hyperbilirubinemic Newborns. Maced J Med Sci 2014; 7 (2): 261-4.
6. Bhargava $O$. Incidence of thrombocytopenia in Hyperbilirubinemic neonates following Phototherapy. Asian J Res Chem 2015; 8 (4): 221-30.

7. Maisels MJ, Kring E. Length of stay, jaundice, and hospital readmission. Pediatrics 1998; 101:995-8.

8. Tawab CAN, Saldanha PR, Mihun HK. Phototherapy induced thrombocytopenia a comparative study among breastfed term and preterm neonates with hyperbilirubinemia. Int J Med Health Sci 2014; 3 (4): 256-60.

9. Narayana S, Aggarwal, Upadhyay A, Deorari AK, Sindh M, Paul VK. Survival and morbidity in extremely low birth weight (ELBW) infants. Ind Pediatrics 2003; 40(2):130-5.

10. Venaktamurthy M, Balaji MD, Reddy TK. A study on effect of phototherapy on platelet count in neonates with neonatal hyperbilirubinemia in a Tertiary Care Rural Hospital. Intl J Contemp Pediatrics 2016; 3 (1): 253-5.

11. Sonawane P, Bhaisara B, Bhatawdekar A. Effect of conventional phototherapy on platelet count in full term and preterm neonates with indirect hyperbilirubinemia - A prospective cohort study. J Med Sci Clin Res 2018; 06 (03): 959- 66.

12. Vafaie $M$, Mirzarahimi $M$, Sadeghieh-Ahari $S$, Enteshari-moghaddam A, Merrikhi $\mathrm{H}$. Incidence of thrombocytopenia following phototherapy in hyperbilirubinemic neonates in Ardabil City. Intl J Contemp Pediatr 2018; 5:2274-7.

13. Khera S, Gupta R. Incidence of thrombocytopenia following phototherapy in hyperbilirubinemic neonates. Med J Armed Forces India 2011; 67(4):32932.

14. Pishva N, Pishva H. Incidence of thrombocytopenia in hyperbilirubinemic neonates during phototherapy. Acta Medica Iranica 2000; 38(1):7-9.

\begin{tabular}{|c|c|c|c|}
\hline \multicolumn{4}{|c|}{ AUTHORSHIP AND CONTRIBUTION DECLARATION } \\
\hline Sr. \# & Author(s) Full Name & Contribution to the paper & Author(s) Signature \\
\hline 1 & Adnan Bashir & $\begin{array}{l}\text { Literature review, Materials handling } \\
\text { compilation of resutls, statistical analysis, } \\
\text { Manuscript write up, Proof reading. }\end{array}$ & \\
\hline 2 & Ashok Kumar & $\begin{array}{l}\text { Materials handling, Interpretation lab } \\
\text { investigations, Manuscript write up, Proof } \\
\text { reading. }\end{array}$ & \\
\hline 3 & Nathumal Maheshwari & $\begin{array}{l}\text { Concept, Materials handling, Collection of } \\
\text { materials, compilation of resutls, statistical } \\
\text { correspondence. }\end{array}$ & \\
\hline 4 & Bilawal Hingorjo & $\begin{array}{l}\text { Literature review, Concept, materials handling, } \\
\text { Interpretation lab investigations, Manuscript } \\
\text { write up, Proof reading. }\end{array}$ & \\
\hline 5 & Shakeel Ahmed & $\begin{array}{l}\text { Concept, Materials handling, Investigation lab } \\
\text { investigations Manuscript write up. Proof rea- } \\
\text { ding. }\end{array}$ & \\
\hline 6 & Saher Fatima & $\begin{array}{l}\text { Concept, Materials handling, Collection of ma- } \\
\text { terials, compilation of restuls, staitistical analy- } \\
\text { sis, manuscirpte write. }\end{array}$ & \\
\hline
\end{tabular}

